\title{
O esclarecimento E A distinçÃo NA ALIMENTAÇÃo: UMA ANÁliSE DA INDÚSTRIA CULTURAL E A FORMAÇÃo DO GOSTO POR CERVEJAS ESPECIAIS
}

Renato Augusto da Silva MONTEIRO*

RESUMO: Colocadas em circulação no mercado, as cervejas especiais se contrapõem às cervejas que passam a ser lidas como comuns. Entre o refinado e o grosseiro, o objeto o qual seja considerado bom ou mau gosto se altera em processos de longa duração. $\mathrm{O}$ esclarecimento gera a partir das condições de existência um sistema de conhecimentos em torno da alimentação que se transforma reiterando a dominação por meio da distinção. Neste estudo, analisamos as estratégias de mediação sociocultural da Ambev no Centro de Experiência Cervejeira da Bohemia (CECB). Nossa questão gira em torno das táticas da indústria cultural e do esclarecimento na formação do gosto por cervejas especiais e sua relação com o habitus e a distinção. Problematizamos a degustação como fórmula geradora de estilos de vida, que produz juízos de gosto que reiteram a auto conservação da aparelhagem social e econômica sob uma aparente liberdade de escolha.

PAlAVRAS-CHAVE: Esclarecimento. Distinção. Indústria cultura. Habitus. Formação do gosto.

\section{Introdução}

A produção e o consumo de cervejas especiais têm crescido no Brasil, se destacando como cervejas que possuem maior quantidade de malte de cevada e de lúpulos especiais em sua composição. As cervejas artesanais normalmente são cervejas especiais, uma vez que utilizam ingredientes considerados de melhor qualidade. Entretanto, o inverso pode suscitar uma confusão semântica, uma vez que nem toda

\footnotetext{
* Universidade Federal do Rio de Janeiro (UFRJ). Instituto de Nutrição Josué de Castro. Departamento de Gastronomia. Programa de Pós-graduação em Educação em Ciências e Saúde do Instituto NUTES (UFRJ). Rio de Janeiro - RJ - Brasil. 21941902 - renatomonteiro@gastronomia.ufrj.br. https://orcid.org/00000002-8662-285X.
} 
cerveja especial é artesanal ou produzida de forma artesanal em pequena escala. Nesse cenário, as cervejas especiais surgem se contrapondo àquelas que passam a ser lidas como cervejas comuns, produzidas em larga escala e impulsionadas pela propaganda, uma das principais táticas utilizadas pela indústria da cerveja no mercado brasileiro.

Diante do crescimento do mercado de cervejas especiais e em função de interesses mercadológicos, a indústria de cerveja passa a direcionar esforços para a formação de um público consumidor interessado em produtos mais sofisticados. Quando as cervejas especiais são produzidas e postas em circulação se apresenta não apenas a possibilidade do consumo de produtos de qualidade supostamente superior, como também do acionamento de signos de distinção que se contrapõem ao consumo de cervejas classificadas como ordinárias. Os conhecimentos sobre a alimentação se configuram em torno de um logos do esclarecimento capaz de conferir distinção por meio de percepções e práticas inerentes a habitus que legitimam determinado estilo de vida. Nesse sentido, propomos problematizar a apropriação de um logos sobre cerveja na construção de uma narrativa mítica pela indústria cultural no que se refere à análise de suas estratégias de produção de sentidos sobre a formação do gosto por cervejas especiais.

Como referencial teórico este estudo propõe construir uma interseção entre o mito e o esclarecimento no contexto da indústria cultural a partir de Theodor Adorno e Max Horkheimer (1985) com o habitus e a distinção de Pierre Bourdieu (2015, 1983), trazendo como bibliografia secundária autores do campo da alimentação. Buscamos, assim, estabelecer relações entre esses referenciais a fim de problematizar a formação do gosto por cervejas especiais nas estratégias da indústria cultural analisando um tour cervejeiro. Ou seja, nos interessa identificar a forma como a indústria cultural atua na construção de uma narrativa sobre bens de consumo pretensamente sofisticados, acionando um conhecimento técnico, logos, por meio da encenação de práticas relacionadas à degustação de cervejas especiais, ocultando os limites situados nas condições de existência de classes que configuram os estilos de vida.

\section{O mito e esclarecimento na alimentação: a dominação do logos}

A Dialética do esclarecimento de Adorno e Horkheimer (1985) marca as bases do berço da Escola de Frankfurt trazendo uma crítica às categorias ocidentais da razão e da natureza. $\mathrm{O}$ conceito de esclarecimento pode ser entendido como um processo no qual se estabelece mais efusivamente distância entre sujeito e objeto pela racionalização discursiva do logos. Segundo Funari (2002), a razão era um conceito essencial para os 
gregos, de modo que a palavra logos, derivada do verbo legein, signfica juntar, e, ao mesmo tempo: palavra, discurso e razão. Assim, o logos enquanto expressão do esclarecimento teria como premissa reforçar a dominação dos humanos sobre a natureza, cindindo esses universos. A dominação sobre a natureza se estenderia de forma ainda mais proeminente à dominação dos humanos sobre os próprios humanos: "o programa do esclarecimento era o desencantamento do mundo. Sua meta era dissolver os mitos e substituir a imaginação pelo saber" (ADORNO; HORKHEIMER, 1985, p.17).

O cerne da origem da dominação se apresentava desde os mitos, se estendendo ao esclarecimento por meio de um processo dialético, que não se daria de forma unilateral. Insurgindo contra os mitos, o esclarecimento carregaria em si fragmentos do próprio mito ao qual buscou suprimir. Moreira (2012) considera que na Odisséia de Homero seria possível encontrar a dimensão racional do logos no nascimento do "protoburguês", embrião da razão que marca a subjetividade da civilização ocidental. Embora Dionísio não seja mencionado, o vinho é um dos fios condutores da narrativa homérica, assumindo diversos papéis, presente em todas as refeições, juntamente com o pão e a carne, selando as relações entre conhecidos e desconhecidos, entre deuses e mortais e entre os vivos e os mortos, bem apresentando sinais de civilidade: "a cratera demonstra que a lição de Dionísio foi aprendida, a bebida deve ser dosada, diluída e regulada" (CARNEIRO, 2010, p.32).

É possível realizar uma leitura da desdionização do mito dionisíaco, como um processo de "apolineamento educativo" para que fosse incorporado aos rituais dos sympósios, pois "uma divindade assim tão próxima e integrada no próprio homem, um deus tão libertário e "politicamente" independente, não poderia mesmo ser aceito pela pólis grega de homens e de deuses tão apolineamente patriarcais e tão religiosamente repressivos" (BRANDÃO, 1987, p.137). Nos sympósios, a embriaguez seria valorizada como um meio de elevar a criatividade poética, grandes poetas quase sempre eram membros das elites e grandes apreciadores de bebidas. Carneiro (2010) escreve sobre a história da embriaguez, sendo o modo de beber nos sympósios um tema recorrente da retórica de filósofos gregos como Aristóteles e Platão. Enquanto ritual de sociabilidade festiva aristocrática ensaiada pela racionalidade, era reiterado nos sympósios a ideia de autocontrole, como uma zona privilegiada e protegida, em oposição ao universo desconhecido da barbárie, pois "através dessas regras, os homens superiores diferenciavam-se tanto dos kakói, dos homens comuns, imersos em seus desregramentos dionisíacos, quanto dos 'bárbaros' não gregos, que bebiam de forma selvagem, ignorando as sutilezas cerimoniais” (FERNANDES, 2004, p.160). 
Os rituais em torno do uso bebidas se apresentavam desde os mitos como uma fonte de angústia para o esclarecimento, tensionando os costumes e delineando a formação do gosto. No campo da alimentação, e mais particularmente no uso das bebidas alcoólicas, é possível identificar a ruptura do esclarecimento em ao menos duas perspectivas: i) mente e corpo e ii) natureza e cultura. A primeira diz respeito aos usos das bebidas alcoólicas e à embriaguez, configurada na cosmologia ocidental sob a influência da ética da temperança em contraposição ao excesso, mais tarde reconfigurados pelo Cristianismo nos pecados capitais. Não exploraremos essa vertente em função da necessidade de utilizar outro recorte teórico, o que fugiria da proposta deste estudo. A segunda, sobre a qual nos debruçaremos, se refere à construção discursiva do esclarecimento enquanto um capital cultural e/ou econômico, no qual o acesso é situado nas condições de existência que engendra habitus, práticas e percepções classificadas e classificadoras do lugar ocupado na hierarquia social. Em uma perspectiva sócio histórica, o mito e o esclarecimento atuam a partir das condições de existência, um sistema de conhecimentos - logos - em torno da alimentação que se altera em processos de longa duração, reiterando a dominação por meio da distinção.

A fim de elucidar a segunda vertente, relacionada à existência de um logos próprio da alimentação, podemos iniciar pela teoria dos humores de Hipócrates (V e IV a.C.), que percorreu a Antiguidade passando pela era medieval europeia e que perdurou até meados da modernidade, constituindo o principal corpo de explicação racional sobre a saúde e a doença baseado nas prescrições médicas das dietas especiais. O vocábulo dieta advém de diaita, em grego significa "gênero de vida", "mais do que um regime alimentar denotava um estilo de vida ou, mais precisamente, um modo regulado de vida", sendo "inseparável de um 'regime' político específico e dos valores a ele associados, entre os quais a noção caracteristicamente helênica do "nada em excesso"" (VARGAS, 2001, p.103). O que se come como "gênero de vida" se relaciona com o estilo de vida no contexto da teoria do habitus proposta por Pierre Bourdieu (2015, 1983), referindo-se às práticas e percepções comuns de classe inscritas nas escolhas condicionadas por determinadas condições de existência.

Existe uma intrínseca relação entre o gosto e a alimentação, sendo a etimologia do vocábulo "gosto" correspondente ao mesmo tempo a ideia de saber e de sabor, caracterizado como sábio aquele que possui a capacidade de discernir entre diferentes sabores. A alimentação pode ser entendida como um imperativo utilitário inalienável diretamente necessário para a sobrevivência humana em todas as épocas e em todas as culturas, de modo que "se deve buscar o desdobramento do termo gosto, do paladar para os juízos de valor, no fato de o trabalho necessário à alimentação anteceder todas as demais produções humanas, materiais e simbólicas" (SCHNEIDER, 2015, p.56-57). 
A teoria dos humores previa a melhor maneira de cozinhar, temperar e comer os alimentos com o intuito de equilibrar os humores do corpo, além de prescrever banhos e dietas para tratar febre (FLANDRIN, 2015a). Outro importante corpus estabelecido na Renascença foi a Cadeia do Ser também conhecida como scala naturae. A Cadeia do Ser era um conjunto de teorias tidas como objetivas na época, "o que veremos, portanto, é que na filosofia natural setecentista, amparada por uma verdade bíblica, o estudo dos animais e homens também se prestava à instrumentalização do antropocentrismo" (SANTOS; CAMPOS, 2014, p.121). Em uma escala hierárquica se amparava uma série de analogias, uma espécie de código adequado para definir a natureza classificando os alimentos entre nobres ou vulgares. A terra seria o elemento mais vil, as árvores frutíferas adequadas às elites, cuja superioridade natural se devia ao fato de os frutos se formarem mais distantes do solo, o que justificava, por exemplo, a goiaba ser considerada uma fruta superior ao morango. Dessa forma, a Cadeia do Ser pode ser entendida como um logos, uma racionalidade cuja narrativa, como observa Grieco (2015), se dava em função de ordenar o mundo natural de maneira inteligível e conferir um valor social aos alimentos, criando em torno da alimentação um código associado às distinções sociais.

A Cadeia do Ser, estágio inicial ou intermediário da nascente ciência moderna ocidental, ainda seria capaz de articular filosofia e teologia natural. Entretanto, "os mitos, como os encontram os poetas trágicos, já se encontram sob o signo daquela disciplina e poder que Bacon enaltece como o objetivo a se alcançar" (ADORNO; HORKHEIMER, 1985, p.20). As investidas contra os mitos e a metafísica buscaram fundar as bases de um pensamento pretensamente universal, guinada que estabeleceu outros parâmetros de produção do conhecimento como o método de Descartes, com significativa influência no ordenamento de práticas e de percepções em torno da alimentação.

Com o desenvolvimento da ciência, as referências à antiga dietética aos poucos se apagariam, desbancando gradualmente a noção médica hipocrática-galênica da teoria dos humores, afrouxando os laços entre a cozinha e a dietética. Como mostra Flandrin (2015b), os cozinheiros passariam a se ater à harmonia dos sabores, antes sabiamente classificados do mais frio para o mais quente na lógica hipocrática-galênica, constituindo uma indicação segura da natureza dos alimentos e de sua digestabilidade. Esse processo libertaria, de certa forma, a gulodice, pois o refinamento da cozinha deixava de visar o mantimento da boa saúde para satisfazer o gosto dos glutões ou daqueles com paladar apurado o suficiente para apreciar as iguarias, sendo peritos na arte de reconhecê-las. Não é à toa que na França, a noção de gosto se desenvolveu no momento em que os progressos da química e da fisiologia experimental negavam a 
antiga teoria dos humores, muito antes que uma nova dietética viesse a se estabelecer de forma sólida. Esse conjunto de circunstâncias teria desviado por três séculos, cozinheiros e consumidores das tradicionais preocupações dietéticas, ainda que ressurgidas mais recentemente com a Ciência dos Alimentos e a Nutrição. A culinária não estaria simplesmente a serviço da gula, do pecado capital, mas do bom gosto, assim como todas as belas-artes, acompanhando os ideais do classicismo. Da culinária surgiria a gastronomia, adotando um sentido mais amplo não restrito a função de resguardar a saúde do corpo. Como propunha o chef Brillat-Savarin (1755-1826), que entre outros chefs franceses organizou a gastronomia como uma disciplina de normas, técnicas e procedimentos, a gastronomia seria "o conhecimento fundamentado de tudo o que refere ao homem, na medida de em que ele se alimenta" (SAVARIN, 1995, p.61).

Até o século XI, a sociedade medieval europeia era pouco refinada com mínima diferença entre lordes e vassalos, crescendo a preocupação entre os nobres de marcar a distância social em relação à plebe a partir dos séculos XI, XII, e sobretudo XVIII, não se tratando mais de afirmar a distinção entre civilizado e bárbaro, mas entre os próprios europeus. O refinamento da etiqueta e dos utensílios foram se tornando meios privilegiados de distinção social, constituindo um novo "estilo de vida" que originaria a "loucura pelas especiarias" rumo às Cruzadas (VARGAS, 2001). Essa "loucura" seria mais tarde substituída pelas luxury foods, como o açúcar, o chocolate e o café, produtos advindos, sobretudo, das plantações da colonização (SCHIVELBUSCH, 1992).

Nesse processo se transformação, se organizariam os conhecimentos em torno da alimentação pautados por um logos capaz de conferir distinção determinando as mudanças nos costumes, na etiqueta e nas normas de comportamento em torno da mesa. Essas mudanças se anunciavam paulatinamente desde a transição da sociedade medieval da nobreza de cavalheiros para a aristocracia das cortes absolutistas. Elias (2011) analisa os tratados e manuais de boas maneiras como o De civilitate morum puerilium, de Erasmo de Rotterdam, que no século XVI teria grande circulação com 30 edições lançadas nos primeiros seis anos de sua publicação. Esses manuais descreviam o comportamento socialmente aceitável, o que funcionava como um meio de introduzir a aristocracia às conversas e ao convívio através do compartilhamento de códigos específicos e da interiorização de normas e valores comuns. Esses costumes que acompanharam o emprego dos utensílios à mesa, como o garfo, bem como a maneira de manuseá-los, se deu de forma lenta e gradual a partir dos estratos mais altos da sociedade para os mais baixos, ditando o que deveria ser feito à semelhança do que era realizado na corte. Os tratados se dirigiam às pessoas que desejavam conhecer os costumes da corte, a exemplo da nobreza provinciana e das classes médias altas, funcionando como um passaporte para o reconhecimento e a ascensão social. 
Em uma abordagem mais contemporânea, poderíamos citar as considerações de Bueno (2016) sobre a alta cozinha ou cozinha culta, que se consolidou na França após a Revolução Francesa, configurada como uma disciplina, um sistema de técnicas de produção de alimentos e de regras. Com o tempo, os estabelecimentos comerciais multiplicaram-se com a migração de cozinheiros das cortes e da aristocracia. Os preceitos compilados por Escoffier (1846-1935) a partir de chefs como Antonin Caramê (1783-1833), Brillat-Savarin (1755-1826) e Grimod de la Reynière (1758-1837) se institucionalizaram e se internacionalizaram em escolas como Le Cordon Bleu, cuja hegemonia passa a ser questionada a partir de 1970 por movimentos de ruptura, mais especificamente a Nouvelle Cuisine e o Slow Food. A partir de então, a tendência de desvinculação da alta gastronomia ao luxo passa a minimizar a importância do requinte e dos produtos caros para enfatizar o talento dos chefs e a simplicidade de menus reduzidos e produzidos com ingredientes locais.

\section{O habitus e questão do gosto na sociologia}

Nesse breve recorrido buscamos propor uma leitura do esclarecimento na configuração de um sistema de conhecimentos em torno da alimentação, um logos cujo acesso está associado às condições de existência que configuram práticas e percepções inscritas no habitus. Para Bourdieu (1983), o habitus é um produto social que mantém esquemas perpetuados ao longo do tempo, garantindo a presença de experiências passadas no pensamento e nas ações presentes, ao passo que também se modifica. Essa visão se aproxima de Elias (2011) no que tange aos padrões os quais se transformam em processos de longa duração, pois como um passado que sobrevive de forma contínua, o habitus se atualizaria por meio de princípios e práticas estruturadas na sociedade e estruturantes na dimensão de cada indivíduo. Incorporado, o habitus chegaria a ser esquecido, gerando práticas espontâneas, atuando como um capital acumulado, capaz de transcender a consciência individual e coletiva como uma conduta razoável ou esperada. Assim, se gerariam práticas e representações previsíveis que antecipam determinado porvir em dado contexto de classes.

Vargas (2001) considera que Elias e Bourdieu, cada qual à sua maneira, avançaram no intuito de ultrapassar antinomias do pensamento social, como as que dividem indivíduo e sociedade, subjetivismo e objetivismo, determinação e livre arbítrio. Ambos evidenciariam as inter-relações entre o controle do corpo e a posição dos agentes sociais, entendendo que os corpos são inscritos em práticas de aquisição de status e estratégias de distinção. Dando maior atenção ao corpo, buscariam ir além da 
perspectiva binária segundo a qual o corpo é visto a partir de um enfoque biologista ou tido como uma expressão tão somente da cultura, um suporte de símbolos. Elias (2011) observou como os processos de longa duração ensejam mudanças de comportamento e de costumes, entendidos como socialmente definidos e historicamente mutáveis. Seu esforço se daria na direção de uma análise da relação entre indivíduo e sociedade, observando tanto sua relação com a personalidade quanto com as estruturas sociais, tomadas como mutuamente dependentes e contextualizadas de acordo com a época. Já em Bourdieu $(2015,1983)$, embora o corpo apareça de forma indireta em sua obra, não sendo uma categoria analítica central, sua contribuição seria bastante elucidativa ao observar que a dedicação ao corpo aumenta à medida em que decrescem suas funções econômicas. O conceito de habitus pode ser entendido como uma tentativa de escapar das perspectivas mecanicistas e dualistas, a exemplo da noção de disposição incorporada. No corpo, como substrato do habitus, se inscreveriam as relações de poder que reproduzem nele o sistema de dominação da sociedade, distanciando-se de modelos que centralizam os valores impostos do exterior aos agentes sociais.

Bourdieu (2015, p.163) analisa os gostos de classes no consumo alimentar francês, destacando os gostos de luxo (ou de liberdade) e os gostos de necessidade, organizando graficamente a seguinte correlação: as condições de existência objetivamente classificáveis (classes de condicionamento) e a posição na estrutura das condições de existência (estrutura estruturante) condicionam habitus (estrutura estruturada e estruturante) que engendram sistemas de esquemas geradores de práticas e atos de percepção/apreciação ("o gosto") que constituem os estilos de vida, sistemas de práticas classificadas e classificadoras dos sinais distintivos ("os gostos”).

$\mathrm{O}$ capital econômico e/ou cultural se associa às condições de existência cunhadas em um logos, que no contexto da alimentação engendra sistemas de práticas e atos de percepção/apreciação de alimentos e bebidas que constituem os estilos de vida, sistemas sociais de classificação de ordem material e simbólica. A formação do gosto se inscreve, assim, em uma complexa rede de práticas e percepções articulada processada em dada estrutura na dimensão individual (estruturante) e coletiva, marcada pelo contexto das condições e contradições socioeconômicas de classe que reiteram a dominação por meio de cânones relativamente organizados em dada cultura. Sobre o gosto, Bourdieu discorre:

O gosto, propensão e aptidão para apropriação - material e/ou simbólica - de determinada classe de objetos ou de práticas classificadas e classificantes é a fórmula geradora que se encontra na origem dos estilos de vida, conjunto unitário de preferências distintivas que exprimem, na lógica específica de cada um dos 
subespaços simbólicos - mobiliário, vestuário, linguagem ou hexis corporal - a mesma intenção expressiva. (SCHNEIDER, 2015, p.165).

Apesar de Bourdieu incorporar o gosto na teoria do habitus, Schneider (2015) considera que ele não deixaria clara a diferença entre gosto e o habitus, utilizando por vezes as mesmas palavras para definir ambos. A formação do gosto aciona o intercâmbio material do corpo humano com a natureza exterior, desde sua origem culturalmente mediada, sendo o ponto de encontro entre sensibilidade e razão, corpo e mente, natureza e cultura, que marcaria a nossa individualidade. Outrossim, o "gosto possui uma função prática tão simples quanto decisiva na relação do sujeito com o objeto: é ele quem atribui ao último, de forma pronta e imediata, a qualidade de útil e inútil, belo ou feio, agradável ou desagradável", sendo "o resultado de uma ação qualquer do objeto sobre os sentidos, capaz de identificar e avaliar, na forma simples, mas vigorosa de um sim ou um não, se o objeto possui o sentido objetivo de ser desejável ou indesejável para os sentidos subjetivos do sujeito" (SCHNEIDER, 2015, p.290). O gosto faria parte de um universo identitário, qualquer que seja, de modo que, enquanto escolha estabelece uma hierarquização valorativa de dimensão ideológica:

O gosto, como escolha, ou hierarquização valorativa das coisas (materiais ou simbólicas), isto é, como medida de seu valor de uso, estando as necessidades básicas de sobrevivência satisfeitas, é uma síntese (inconsciente) da expressão distintiva de cada coisa (de sua materialidade) e das experiências singulares concretas da percepção individual, mediada pelo conjunto de valores simbólicos coletivos (cânones mais ou menos formalizados de uma cultura); esta mediação é o que lhe atribui necessariamente uma dimensão ideológica. (SCHNEIDER, 2015, p.159).

Uma questão que avança na análise de Schneider (2015) se refere à relação entre o gosto e a disparidade de forças com que atua o capital econômico ao se confrontar com indivíduos em particular. Os valores simbólicos e os cânones não seriam absolutos ou eternos, como o habitus e o gosto, na qual a mudança seria delimitada pelo modo de produção hegemônico e pela estratificação de classes. Na formação do gosto, os recursos materiais e o repertório simbólico comum, desigualmente distribuídos, se traduzem em interesses convergentes e conflitantes em meio à luta de classes; em última instância determinada pelo lugar ocupado pelos indivíduos nas relações de trabalho, o que não se processa de forma linear ou mecânica. As experiências estruturantes na dimensão da singularidade individual seriam condicionadas à determinada estrutura, que se apresenta como um campo heterônomo de possibilidades que delimita a margem 
de atuação do gosto, que "é e não é culturalmente determinado, assim como é e não é determinado pelas experiências concretas dos sujeitos" (SCHNEIDER, 2015, p.292). O gosto popular seria visto (ou tido) como supostamente natural, sendo, entretanto, resultado de um intrínseco processo em que o capital se apresenta numa disparidade de forças diante do indivíduo, produzindo, informando e colocando em circulação apenas o que the possibilite acumular e reproduzir. $O$ autor investe na análise das infotelecomunicações (ITCs) que agiriam nos planos ideológico, psíquico (afetivo/emocional) e econômico por meio de uma ação pedagógica difusa, lúdica e informativa.

A disparidade de forças com que o capital econômico atua diante do indivíduo se apresenta como uma questão sobre a qual nos debruçamos na análise no Centro de Experiência Cervejeira da Bohemia (CECB), um espaço de divulgação da cultura e da tecnologia de produção de cerveja, pertencente a uma empresa multinacional com elevado poder econômico. A hipótese inicial era a de que as estratégias de mediação utilizavam mecanismos do que Adorno e Horkheimer (1985) entendem como indústria cultural, uma comunicação destinada às massas, da qual participariam milhões de pessoas, atuando por meio de métodos de reprodução e de disseminação de bens padronizados para satisfação de necessidades iguais. Para os autores, a técnica conquistaria seu poder na sociedade, sendo exercida pelos economicamente mais fortes, a racionalidade técnica reiteraria essa dominação. Nesse sentido, problematizamos a adoção de uma narrativa cunhada em determinado logos sobre cerveja nas estratégias de mediação da Ambev no CECB, a fim de analisar a produção de sentidos sobre o gosto na experiência de consumo de cervejas especiais da marca Bohemia.

Antes, porém, de apresentar e discutir os dados da pesquisa é importante situar a partir de Gazurek (2012) as diversas tendências da sociologia e antropologia do consumo. Além das teorias de Bourdieu e Baudrillad, que em vários pontos se aproximam, como a estrutura de classe existente e a distinção, tendências mais recentes, como McCracken, vêm enfatizando o caráter identitário do consumo se concentrando no processo de apropriação de objetos pelo indivíduo. Outras tendências, como a de Lipovetsky, enfatizam as características subjetivas e pessoais da sociedade do hiperconsumo. Cabe situar que essas abordagens partem da análise de sociedades cuja organização difere da sociedade brasileira, além dos aspectos subjetivos do consumo, é importante considerar que nossa análise se desenvolve em uma sociedade na qual o conflito de classes se apresenta em uma estrutura profundamente desigual. 


\section{Delineando a pesquisa: a visitação no tour cervejeiro}

Ao todo o CECB possui cerca de nove espaços expositivos, salas de visitação, de modo que nos concentramos nas mediações socioculturais da sala na qual ocorre a primeira degustação de cerveja intitulada Sala da Transformação. A pesquisa de cunho qualitativo utilizou como método a análise de conteúdo. A análise do conteúdo é um método de pesquisa usado para descrever e interpretar o conteúdo de documentos e textos variados, conduzida por descrições que contribuam à reinterpretação de mensagens e à compreensão de seus significados em um nível que esteja além de uma leitura comum (MORAES, 1999). O ponto de partida da análise do conteúdo é a mensagem, que expressa um significado e um sentido que não podem ser considerados como um ato isolado, tornando-se indispensável observar que a emissão de mensagens está necessariamente articulada com as condições contextuais. Essas dizem respeito à evolução da humanidade, às situações econômicas e socioculturais nas quais os emissores se inserem, estando as mensagens carregadas de componentes cognitivos, afetivos e valorativos historicamente mutáveis (FRANCO, 2012).

A pesquisa se apoiou na perspectiva de Bardin (2011), cuja análise do conteúdo se organiza em torno de três momentos: i) pré-análise, ii) exploração do material, iii) tratamento dos resultados, inferência e interpretação. A pré-análise consistiu em operacionalizar as ideias iniciais começando por uma leitura panorâmica da visitação. Para isso foram realizadas sessenta e seis voltas completas no tour cervejeiro que durava em média uma hora e uma hora e meia, o que possibilitou a imersão no campo e a formulação dos objetivos.

O objetivo deste estudo se refere a analisar a produção de sentidos e sua relação com a formação do gosto por cervejas especiais em um espaço de divulgação associado ao entretenimento, que pertence a uma multinacional líder no mercado de cervejas. Nossa hipótese era a de que as estratégias utilizadas pela Ambev se apresentavam na perspectiva da indústria cultural adotando uma construção discursiva esclarecida baseando-se em certo logos sobre a técnica de produção e degustação de cerveja capaz de justificar o consumo de cervejas especiais da marca Bohemia.

A exploração do material se deu a partir da elaboração de um corpus da pesquisa que pode ser entendido como o conjunto de documentos submetidos a processos analíticos, o que implica a realização de escolhas e seleções. Para a constituição dos dados da pesquisa, transcrevemos os textos advindos de painéis, aparatos e vídeos. Foi utilizado para registro um caderno de campo. O tratamento dos dados, bem como as 
unidades de contexto da visitação levaram a resultados que se constituíram a partir das inferências feitas do referencial teórico.

Nesse processo, a interpretação foi submetida à análise dialogando com o referencial teórico apresentado anteriormente. Os indicadores que fundamentaram a interpretação foram construídos e organizados de acordo com a sequência em que se desenvolvia a visitação, que na Sala da Transformação era guiada por monitores, terminando com a degustação de uma cerveja especial, uma das variantes da marca Bohemia.

As unidades de contexto foram trazidas de observações da pesquisa de campo que pudessem contribuir para uma visão panorâmica do conjunto, ou seja, que dissessem respeito ao comportamento padrão ou recorrente entre os visitantes. Os monitores não foram abordados e nem suas falas transcritas, uma vez que não recorremos a entrevistas ou a descrição de casos específicos. Optamos por excluir a realização de entrevistas, uma vez que julgamos suficiente a quantidade de informações extraídas das observações para constituir um campo fértil de inferências.

No CECB, o percurso se desenvolve a partir da visitação nas salas de livre circulação e nas de mediação guiada por monitores. O espaço é dividido em salas expositivas, de modo que, em algumas salas, a visitação é livre, podendo o visitante aprofundar o conhecimento nos aparatos interativos mediante seu interesse e pelo tempo que julgar necessário. $\mathrm{O}$ tempo do percurso completo dura cerca de uma hora a uma hora e meia, sobretudo a depender do tempo pelos visitantes nas salas de livre circulação. Essas contam com painéis e com aparatos diversos, que, ao serem tocados (touch screen) aprofundam a temática abordada.

$\mathrm{O}$ valor do ingresso no CECB pode ser considerado elevado em relação a outros atrativos da cidade de Petrópolis-RJ, como também diante dos valores tradicionais cobrados nos espaços de visitação na cidade. $\mathrm{O}$ valor do ingresso é em média três vezes maior do que o cobrado no Museu Imperial, incluindo o acesso ao tour e duas degustações de cerveja. Mesmo com um ingresso cujo valor pode ser considerado elevado, o empreendimento parece ser um sucesso, como pode ser observado pela avaliação do público no site Tripadvisor, com a maioria das avaliações concentrando-se nas opiniões excelente e muito bom.

Cervejas especiais: notas sobre o logos da distinção

Em relação ao contexto é importante situar que a Ambev é uma empresa multinacional líder do mercado de bebidas no Brasil, cujo mercado de cervejas é 
caracterizado pelo oligopólio, sendo responsável por cerca de $68 \%$ da produção de cerveja do país ${ }^{1}$. A Ambev surgiu em 1999 quando se deu a controversa união entre duas grandes cervejarias (Brahma e Antárctica), uma fusão doméstica motivada por fatores estratégicos e operacionais, principalmente na busca de sinergias e de crescimento internacional. Desde então, a Ambev se associou a outras empresas, como a belga Interbrew e a americana Anheuser-Busch, formando uma das maiores companhias de capital aberto do mundo com o controle de um terço do mercado mundial (CARMARGOS; BARBOSA, 2005). Tanto a Brahma quanto a Antárctica atuaram ao longo do século XX nas arenas do poder político, como demonstra a pesquisa de Fonseca Filho (2008) que analisa a atuação do Sindicato Nacional da Indústria da Cerveja fundado em 1948. No Brasil, a Ambev adquiriu microcervejarias, como a Colorado, o que demonstra o interesse da companhia em expandir sua atuação no segmento de cervejas especiais e diversificar sua produção para além dos estilos mais comuns de cervejas. O aumento do poder aquisitivo das famílias, a melhoria da distribuição de renda e a sofisticação do padrão de consumo seriam alguns fatores explicativos do crescimento do setor de cervejas especiais no Brasil (CERVIERI JÚNIOR et al., 2014).

A Sala da Transformação busca significar o processo de produção da cerveja na fase fria, ou seja, quando ocorre a transformação do mosto cervejeiro com a produção de álcool pela ação das leveduras. A mediação era guiada por monitores e organizada na sequência dos aparatos (resfriamento, fermentação, maturação e filtração). Os visitantes aguardavam na sala anterior e entravam em grupo, sendo recebidos pelo monitor que se apresentava e discorria sobre o processo de produção a partir de aparatos explicativos que davam suporte à mediação. A cenografia se assemelhava à perspectiva da terceira geração de museus de ciência e tecnologia, os science centers, sobretudo, pelo aspecto futurista e pelo intuito de explicar conteúdos de cunho científicotecnológico (VALENTE, 2009).

Apesar de se assemelhar a um centro de ciências, os conteúdos não eram aprofundados, pois as estratégias da indústria cultural se concentram no grande público, que aqui se volta aos consumidores, e não aos produtores de cerveja, sendo suficiente para a maioria dos visitantes dispor de algumas noções sobre o processo de produção de cerveja, pois "o que se poderia chamar de valor de uso na recepção dos bens culturais é substituído pelo valor de troca; ao invés do prazer, o que se busca é assistir e estar

\footnotetext{
${ }^{1}$ Segundo Cervieri Júnior et al. (2014) quatro companhias responderam por cerca de $98 \%$ do volume total de cerveja produzida, se apresentando a divisão do mercado da seguinte forma: Ambev $(67,9 \%)$, Cervejaria Petrópolis (11,3\%), Brasil Kirin (10,8\%), Heineken $(8,4 \%)$ e outros $(1,6 \%)$.
} 
informado, o que se quer é conquistar prestígio e não se tornar um conhecedor" (ADORNO; HORKHEIMER, 1985, p.131).

A postagem de fotografias ao longo da visitação nas redes sociais reforça a dimensão da subjetividade, do desejo de obter uma imagem positiva de si, como alguém bem informado que circula em um ambiente legitimado a dizer algo sobre cerveja e sobre a suposta forma adequada de consumi-la. O prestígio seria reforçado pela degustação, que diferente do ato de beber é voluntário e reflexivo, pois busca analisar as qualidades da bebida, submetendo o líquido aos sentidos a fim de julgá-lo e descrevêlo (SANTOS; SANTANA, 2012). O termo degustação se aproxima da experiência do aprazível, da submissão do líquido aos sentidos para descrevê-lo de forma criteriosa com o objetivo de avaliá-lo (HOUAISS; VILLAR, 2001). A degustação pode ser entendida como uma expressão do esclarecimento na medida em que representa um logos mais ou menos organizado do conhecimento que determina a forma de descrever a bebida a fim de classificá-la. O consumo do que se bebe (bebida/cerveja) enquanto produto e a forma como se bebe (comportamento/práticas) são elementos classificantes e classificadores do consumidor.

A degustação de bebidas alcoólicas, como a cerveja, envolve o uso de álcool etílico, substância química produzida mediante a fermentação do açúcar encontrado em vários produtos de origem vegetal, realizada por fungos unicelulares (VENTURINI FILHO, 2010). O consumo de bebidas alcoólicas desde sua origem teve grande destaque nas festas e nas cerimônias. Joannès (2015) descreve os banquetes mesopotâmicos que aconteciam nas assembleias de deuses, nos quais se tomavam decisões importantes, como no poema babilônico da criação Enouma Elish. Por meio da alegria causada pela cerveja e pela saciedade dos corpos, os convivas acreditavam que os deuses se manifestariam entre eles, realizando acordos durante os banquetes que simbolizavam as alianças desde o núcleo familiar até o topo da hierarquia estatal. A recusa do compartilhamento de bebidas, como o ritual que envolve o brinde, poderia desde aquela época, como nos dias atuais, ser interpretado como um sinal de hostilidade.

Acredita-se que as bebidas alcoólicas tenham surgido relativamente ao mesmo tempo a partir das matérias primas disponíveis em diferentes partes do mundo. O uso de bebidas alcoólicas remonta aos mitos e aos ritos da pré-história, sendo o conceito de fermentação ambientado no discurso científico no século XIX pela refutação da teoria da geração espontânea por Louis Pasteur. O rito seria a práxis do mito e o mito uma potência posta em ação pelo rito, processo que envolve o poder de dominar determinados objetos como uma forma de significar e explicar o mundo imbuído de dada temporalidade: "o tempo sagrado do mito não se apresenta como no tempo do profano, cronológico e linear, mas um tempo circular voltando sempre a si mesmo, a 
reversibilidade do tempo sagrado seria um valor significativo", assim, "o profano é o tempo da vida; o sagrado, o tempo da eternidade”. (BRANDÃO, 1986, p.40).

As primeiras cervejas eram compartilhadas utilizando canudos de junco que serviam para filtrar grãos, palhas e outros fragmentos que ficavam suspensos. Antes do surgimento da cerâmica, a fermentação da cerveja era realizada em sacos de couro, estômagos de animais, árvores ocas, grandes conchas ou em recipientes de pedra. Os rituais em torno do consumo de bebidas alcoólicas fazem parte de processos de socialização. Mesmo após o surgimento de copos, o uso de canudos persistiria por muito tempo, o que sugere a função social das bebidas associada a um ritual, prática que se perpetuou mesmo quando não era mais necessário o uso de canudos. Até o século XIX era raro entre nós que cada pessoa tivesse seu próprio copo à mesa, como assinala um guia americano ilustrado de boas maneiras: "duas pessoas podem beber no mesmo copo, mas essa intimidade não deve ser imposta a ninguém” (VISSER, 1989, p.25).

A degustação de bebidas pode ser entendida como uma técnica que se inscreve no contexto das normas de comportamento, que se transformam ao longo do tempo como previa Nobert Elias (2011). No contexto da gastronomia, diz respeito à organização de um corpus de conhecimentos estabelecido por grupos de especialistas. Algumas entidades, como a Associação Brasileira de Sommeliers, oferecem cursos para o público interessado em vinhos para saber, por exemplo, como analisar a bebida e preencher a ficha de análise sensorial pelo método Giancarlo Bossi, capaz de classificar a bebida, utilizando a linguagem matemática para dar nota à experiência dos sentidos.

Entretanto, o que está em jogo na degustação do CECB, produzida em função de uma encenação rápida e adaptada ao padrão das massas, facilmente assimilável, como ocorre na indústria cultural, é a possibilidade de conhecer e de propagar determinada experiência que classifique o consumidor, distinguindo-o socialmente a partir do uso de um produto pretensamente especial. Essas táticas da indústria cultural se organizam em torno de um suposto conhecimento técnico - logos - cujo acesso a esse capital cultural se encontra relativamente distribuído nas classes mais altas ou nas que possuem acesso a bens mais sofisticados (gosto de liberdade), o que ocorre em função das condições de existência possibilitando o acesso à práticas e percepções que delimitam os estilos de vida. Assim, o bom bebedor aqui não se distingue pela quantidade de cerveja ingerida, mas pela capacidade de apreciá-la, de ser detentor ou não de certos signos de consumo compartilhados através de habitus.

Ao término da apresentação das etapas do processamento de produção, enfim, a cerveja estaria pronta, sendo perguntado aos visitantes se gostariam de fazer a prova da mesma. O silêncio que acompanhava a explicação sobre o processo de produção cedia lugar, então, a manifestação do público permeada por certa euforia, dando a todos 
um lugar no espetáculo e a cada indivíduo adulto o direito a uma taça de cerveja para compor a cena. Como na indústria cultural, o anúncio da degustação anteciparia uma necessidade prevista e criada para que fosse saciada naquele momento. De modo geral, os visitantes atendiam ao convite assiduamente, lançando toda sorte de expectativas em "tiradas" criativas, nas quais afirmavam o interesse em realizar a "árdua" tarefa, como se, independente de conhecer ou não o processo de produção estivessem aptos à experiência do gosto, ao compartilhamento de habitus apresentado como o passaporte para a distinção.

A primeira degustação era o ponto auge do percurso, como se fosse aberta uma espécie de porta da esperança, uma porta secreta da qual um monitor saía com um carrinho de cervejas servidas em taças. Após cerca de uma hora imerso em toda sorte de narrativas sobre cerveja, podemos imaginar que não seria difícil ceder ao convite, de modo que raramente sobrava uma taça cheia. A sobra do não bebedor poderia ser contemplada pela ajuda de um amigo, daqueles que não fossem desperdiçar. Ao longo do percurso, seriam comuns brincadeiras que giravam em torno do tema da embriaguez, mormente calcadas na imagem do ébrio, do boêmio, como aquele que no grupo, formado por amigos e/ou familiares, fosse tido como o entendido do assunto no que se refere ao consumo mais assíduo de cerveja. Portanto, a indústria cultural atuaria de tal forma que não haveria motivos para resistir à encenação diante da abertura da Bohemia da Fonte - uma espécie de parque de diversão dos adultos. A espetacularização remete ao inusitado, à surpresa, como se os visitantes tivessem alcançado o país de Cocagne, sob a promessa de preencher a sensação de vazio simbólica e materialmente significada pela degustação. A degustação atua, assim, criando uma elaboração discursiva capaz de justificar juízos de gosto sobre o que seria raro (cervejas especiais) diante do comum (cervejas de massa), aqui marcada pelas estratégias de interesse de reprodução do capital.

A encenação do brinde era comumente registrada peles visitantes, não raro, ao lado da Bohemia da Fonte. Nesse sentido, podemos estabelecer uma relação com a análise do McDonalds realizada por Fontenelle (2013) quando problematiza o fetichismo da marca nos tempos atuais, sendo a marca tomada para significar a si mesmo, preenchendo a sensação do vazio ao dizer quem somos e onde estamos, pois "não basta tomar refrigerante, tem que ser Coca-Cola, não basta fumar cigarro, tem que ser Marlboro, não basta comer hambúrguer, tem que ser Mcdonalds" (FONTENELLI, 2013, p.285), e por que não dizer, não basta ser cerveja tem que ser Bohemia e de preferência das variantes especiais, tomadas na "fonte", legitimando os bebedores como peritos da arte de degustar. A autora problematiza se, de fato, racionalmente ainda acreditaríamos nas marcas veiculadas pela propaganda mesmo sabendo que a 
propaganda é falsa, da mesma forma que os publicitários saberiam que as pessoas sabem, sendo a marca fetichizada para dizer quem somos na sociedade de consumo.

A marcação do que seria considerado nobre ou vulgar, refinado ou grosseiro, no mercado de cervejas, pode ser observado pelo consumidor nas prateleiras do supermercado, significando o lugar social e o estilo de vida de indivíduos e grupos a partir das escolhas de consumo. Assim, não seria de se estranhar que, tanto no Brasil como no exterior, seja cada vez mais corriqueiro o consumidor se deparar com dois tipos de cervejas. De um lado, as cervejas vendidas geralmente em fardos de lata, ditas comuns e facilmente identificadas nos comerciais de TV e, de outro, cervejas os quais os rótulos o consumidor não estaria tão acostumado, não sendo identificáveis por meio de nenhum marketing que o consumidor possa se lembrar (BELTRAMELLI, 2012). Vale situar que a escolha da prateleira não se processa deslocada das condições de existência, pois o acesso aos produtos dos gostos de liberdade não é da mesma forma acessível aos que estão limitados aos gostos de necessidade.

A mediação de outras salas de visitação do CECB poderia levar o consumidor a uma confusão semântica entre cervejas artesanais e especiais, investindo na imagem de uma cervejaria que foi fundada no século XIX por imigrantes europeus, como é caso da Sala do Mestre Cervejeiro. Nessa sala era possível encontrar, bem como se identificar com a imagem da família Kremer de origem alemã que fundou a cervejaria em PetrópolisRJ, uma cidade associada à nobreza da família real. Na parede central da sala, a marca Bohemia em letreiro neon estaria sob uma fotografia da família em preto e branco com molduras douradas, utilizando recursos do efeito pátina, a inscrição de signos da passagem do tempo nos produtos (ALMEIDA; ROCHA, 2008). A construção de uma narrativa sobre uma fábrica secular e de origem familiar europeia destoa da lógica de acumulação capitalista de uma empresa multinacional como a Ambev. A Cervejaria Bohemia foi adquirida na segunda metade do século XX, sendo sua história e personagens da família Kremer apropriados pelas estratégias do CECB na construção de uma narrativa mítica sobre a marca.

O princípio da indústria cultural se organiza para que as necessidades sejam satisfeitas, devendo o espectador nada deixar escapar diante do estímulo especializado, de maneira que "ninguém tem o direito de se mostrar estúpido diante da esperteza do espetáculo; é preciso acompanhar tudo e reagir com aquela presteza que o espetáculo exibe e propaga" (ADORNO e HORKHEIMER, 1985, p.114). O controle da indústria cultural sobre os consumidores seria mediado pela diversão, pela hostilidade por tudo aquilo que seja mais do que diversão, o acionamento de conhecimentos sobre a produção de cerveja se apresenta na medida em que legitima uma elaboração discursiva sobre o gosto, produzindo juízos de gosto que justifiquem a distinção. 
A promissória do prazer na indústria cultural seria prorrogada indefinidamente, expondo repetidamente o objeto do desejo ao longo das salas de exposição até a degustação, quando a cerveja enfim poderia ser provada. Essas táticas se fundariam na promessa da satisfação de necessidades criadas, uma possibilidade de fuga do cotidiano; satisfação que, entretanto, se apresenta como uma promessa rompida, pois os visitantes enquanto consumidores ocupariam cada qual em função de uma demanda de mercado, o lugar que lhes couber na posição de seu level, ou seja, nas bases determinadas pelas condições de existência dadas pela estrutura socioeconômica.

$\mathrm{Na}$ degustação as cervejas não eram servidas em copos, mas em taças, significando material e simbolicamente os costumes e as normas de comportamento que revelam habitus. Nesse contexto, o visitante poderia se perguntar sobre a forma adequada de manusear a taça, se deveria pegá-la pela haste ou pelo bojo, o que requer pensar no compartilhamento de conhecimentos, de cânones mais ou menos estabelecidos pela cultura, onde se encontra a expressão do esclarecimento. Destarte, a degustação poderia revelar a sensação de embaraço descrita por Elias (2011) de forma mais evidente entre os que não compartilhavam práticas e percepções comuns a certos habitus. Os conhecimentos sobre cerveja como a produção, os estilos e as normas de comportamento, eram apresentados na medida em que cumprissem o objetivo de formar consumidores capazes de distinguir material e simbolicamente as cervejas especiais das comuns, dispondo de uma narrativa mítica apresentada por meio de um logos que permitisse justificar a "escolha".

A degustação por outro lado podia representar, sobretudo em relação à explanação técnica sobre a produção que a antecedia, um convite à libertação dos gostos de necessidade, da gastronomia enquanto arte, de se ter ou não certo domínio de conhecimentos sobre a produção ou os estilos de cerveja, enfim, era chegada a hora de beber. Assim, o sucesso da experiência cervejeira funcionaria como um ato cultural legitimador que mascara as contradições de classes. Pois, mesmo que alguns visitantes pareçam reconhecer a elaboração discursiva segundo a qual as cervejas degustadas seriam de bom gosto, saberiam enquanto consumidores, que essas não passariam a integrar seus habitus, como se, apesar do glamour ou mesmo em sua função, as cervejas especiais não fossem para o seu level. Ou seja, saberiam como a qualquer outro produto distinguir as cervejas que estariam ou não ao seu alcance, notabilizando os limites das condições sociais e econômicas nas quais se inscrevem as escolhas que dão sentido às práticas sociais.

Em campo, alguns visitantes poderiam demonstrar curiosidade, quiçá preocupação, com o preço das cervejas degustadas, o que nos leva a pensar que refletiam 
acerca daquele produto fazer ou não parte de seus repertórios etílicos, atuando as estratégias da indústria cultural de modo a camuflar as contradições de classe. Um exemplo é a cerveja da marca Bohemia do estilo IPA, uma das cervejas especiais servidas na degustação e que tem mais lúpulo na receita, o que poderia causar maior estranhamento em alguns visitantes ou, mesmo, reprovação, em função da percepção mais intensa do amargor. Destoaria, pois, das cervejas mais comuns, tais como das marcas Skol, Brahma e Antártica, também da Ambev, que podem ser caracterizadas como Standard American Lager (BJCP) ${ }^{2}$, um estilo de cerveja com pouco ou nenhum aroma de malte, baixo amargor, cor palha muito clara até amarelo médio, colarinho espumante e raramente persistente, sendo límpida, de corpo muito leve devido à alta quantidade de adjuntos como arroz e milho.

A mudança dos costumes e das normas de comportamento ocorre em processos de longa duração, partindo das classes mais abastadas para as mais populares. Essa perspectiva pode ser observada na pesquisa de Marques (2014) que analisa o desenvolvimento da cervejaria Brahma nas primeiras décadas do século XX na cidade do Rio de Janeiro-RJ, cujo crescimento levou à gradual extinção de pequenas cervejarias que produziam de forma artesanal ou manufatureira. Se, naquele momento, o chopp Brahma de cor dourada e translúcida acionava signos relacionados à distinção, legitimando o estilo de vida da belle époque carioca, atualmente a cor das cervejas especiais, normalmente de coloração mais escura, tais como cobre, avermelhada e marrom, passam a cumprir esse papel, sobretudo, as cervejas da família de alta fermentação, as cervejas "Ales". A autora descreve uma geografia do lazer que marcou naquela época os bares e restaurantes da cidade, que pensada a partir de uma geografia atual divisaria bares e restaurantes entre os que servem cervejas de casco, como o litrão, daqueles que possuem cardápios de cervejas especiais, bem como pratos para harmonizar. Como observa Bourdieu (2015), ao passo que cresce a distância objetiva das necessidades mais urgentes, uma vez preenchidas, se tornam banais ou comuns, surgindo outros atributos que passam a funcionar como fator de distinção. É o que ocorre no caso da loucura pelas especiarias na Europa medieval, pois, no momento em que se tornam comuns e acessíveis, deixam de figurar material e simbolicamente como distintivas; o que faz com que, mais tarde, sejam substituídas por outros produtos como as luxury food's e assim por diante (SCHIVELBUSCH, 1992).

As características das cervejas especiais e das cervejas de massa colocam em questão o acesso a esses bens de consumo, que na experiência da degustação, emoldurada pela sensação do acaso e de encantamento, produz sentidos que ocultam as

\footnotetext{
${ }^{2}$ O Beer Judge Certification Program (BJCP) é um guia internacional de estilos de cerveja.
} 
contradições de classe, como se todos na vida real pudessem fazer parte do espetáculo. Como entende Schneider (2015, p.290), na formação do gosto "o desenvolvimento desses sentidos é fruto da experiência, ou melhor, de um conjunto de experiências singulares. A oportunidade de se ter ou não essas experiências, com que frequência e em qual contexto etc., são fatores socialmente condicionados". A incidência de um campo heterônomo que delimita a margem de determinação do gosto se estabelece pela distribuição desigual dos recursos materiais e do repertório simbólico, sendo a posição dos consumidores determinada, em última instância, pelo lugar que ocupam nas relações de trabalho, que lhes dá acesso à parte da produção posta em circulação. Assim, a dessemelhança de forças entre o potencial de uma elaboração discursiva pretensamente universal, como ocorre no CECB, um espaço que se legitima a construir narrativas sobre cerveja, se confronta com a experiência sensível do indivíduo. A marca se torna um refúgio ilusório capaz de produzir identidades ou recuperar a identidade perdida diante da cultura tornada descartável (FONTENELLE, 2013). Por isso, as identidades promovidas pela indústria cultural se tornam tão atrativas, sendo menos aflitivo e mais agradável escolher entre padrões prontos, entre as variantes de cervejas especiais da marca Bohemia servidas no CECB, que compunham a "leitura do cardápio" sob a ilusão da autonomia de escolha.

$\mathrm{Na}$ degustação, a posse da taça poderia dar a impressão de que era uma peça promocional, uma oferta material condicionada à compra do ingresso, já que no tour alguns visitantes perguntavam se poderiam levá-la, o que reforça a ideia de que os visitantes se perceberiam imersos em um espaço da propaganda e do comércio de produtos, de forma que a taça seria desejada como testemunho material da experiência. Ao pegar a taça de cerveja, os visitantes se voltavam para seus acompanhantes a fim de realizar o brinde, pois brindar não é algo que se faça sozinho. A palavra brinde pode se referir tanto ao efeito de comemoração e êxito, de votos a alguém ou à saúde de alguém, quanto a um objeto que se presenteia (HOUAISS; VILLAR, 2001). O costume de brindar está associado ao compartilhamento de signos de hospitalidade, de modo que brindare viria do alemão ich bringe dir's que significa "eu trago a você" (VISSER, 1989).

De todo modo, a posse da taça na degustação condicionava ao brinde, ao círculo entre os quais se dava certo compartilhamento de signos de proximidade, acionando a possibilidade de se brindar ao outro e ser pelo outro brindado. $\mathrm{O}$ brinde parecia fazer parte da degustação de forma incorporada aos costumes, como um gesto relativamente universalizado na cultura, emoldurando a experiência que busca marcar a distinção do que seja considerado raro e refinado, enfim, daquilo para o qual se destinava o ritual de uma degustação. Assim, os visitantes com sua taça na mão ergueriam os braços com sua 
turma se posicionando para o brinde comumente registrado por uma câmera de celular. Os sorrisos poderiam antecipar certo padrão que busca demonstrar o exitoso prazer da experiência, o testemunho do idílico parque de diversão do universo adulto, postado com entusiasmos nas redes sociais. A indústria cultural cumpre a função de satisfazer desejos criados e preenchidos, sendo o acaso planejado sob a aparência de surpresa diante do qual agimos como se não soubéssemos, embora saibamos, que a marca é uma ilusão, "não estamos falando de uma falsa representação da realidade ou da falsificação da realidade, pelo contrário essa é a nossa realidade" (FONTENELLE, 2013, p.293).

\section{Considerações finais}

Nesse estudo buscamos problematizar as estratégias da indústria cultural ao longo do percurso de um tour cervejeiro, no qual descrevemos a encenação de habitus de consumo de cervejas especiais, práticas classificadas e classificadoras, apresentando a degustação como uma fórmula geradora de estilos de vida. Sob a promessa de satisfazer desejos previstos e antecipados, o consumo de cervejas especiais emergia como um ato cultural legitimador, padronizado e organizado em função das novas demandas de mercado. Embora a distinção permaneça, o objeto que a legitima se altera em processos de longa duração assumindo novas configurações. Assim, quando certos produtos se popularizam (cervejas de massa) deixam de figurar como bens distintivos e a distinção passa a ser significada por outros produtos (cervejas especiais) e, porque não dizer, marcas (Bohemia).

Entretanto, a margem que delimita a formação do gosto se refere a um repertório comum entre consumidores que ocupam posições distintas em uma estrutura social e econômica desigualmente distribuída. As estratégias utilizadas pelo capital atuariam na dimensão subjetiva em uma dessemelhança de forças diante do indivíduo, produzindo uma narrativa mítica como se o gosto por cervejas especiais, bem como o habitus inerente a esse consumo, se desse unicamente em função do desejo ou do reconhecimento da qualidade do produto. Dessa forma, ocultaria as contradições inerentes à estrutura de classes que delimita o acesso aos bens de consumo, sendo a suposta escolha justificada por um logos capaz de conferir distinção. Apesar da narrativa encenada na degustação gerar potencial de reconhecimento do logos enquanto lócus de distinção do bom gosto, alguns visitantes podiam julgar se as cervejas especiais degustadas passariam - ou não - a integrar seus repertórios etílicos. Perceberiam, assim, que a escolha da cerveja, como a de qualquer outro bem de consumo, teria o acesso condicionado ao lugar que ocupam em meio ao conflito de classes. 
A degustação enquanto uma expressão do esclarecimento se refere a um corpus de conhecimento pretensamente universal, que parte na estrutura social de um movimento verticalizado no sentido de cima para baixo. A formação do gosto, ou do que é eleito como bom gosto, se apresenta em uma narrativa mítica do esclarecimento como o que seria capaz de justificar o comportamento socialmente desejável na caracterização de costumes e normas de comportamento. Na indústria cultural, a encenação de habitus de degustação de cervejas especiais atua na formação do gosto com o objetivo de conferir distinção a bens de consumo (cerveja especial) simbolicamente significados pela marca (Bohemia), o que se estende aos consumidores, como se através do consumo se tornassem de forma semelhante bebedores especiais.

A elaboração de juízos de gosto entre o raro e o comum, entre o refinado e o grosseiro, buscaria ocultar as contradições de classes inerentes às condições de existência que conferem sentido às escolhas, às práticas e às percepções inscritas no habitus. A formação do gosto na indústria cultural reiteraria, assim, a auto conservação da dominação social e econômica, na qual o capital produz e faz circular apenas o que lhe assegure a reprodução, ainda que sob uma aparente liberdade de escolha.

\section{The CLARIFICATION AND DISTINCTION IN FOOD: AN ANALYSIS OF THE CULTURAL INDUSTRY AND THE DEVELOPMENT OF TASTE BY SPECIAL BEERS}

ABSTRACT: Brazil's premium beer market has been on a significant rise, which labels traditional beer brands as regular brands. Between refined and common, the definition of what is considered good and bad taste is a long-term change. Enlightenment engenders, based on conditions of existence, a knowledge system around food which transforms itself by reiterating domination through distinction. In this study we shall analyze the sociocultural mediation strategies used by AmBev at Centro de Experiência Cervejeira da Bohemia. Our topic revolves around the tactics used by the cultural industry in the development of a taste for premium beer, as well as its relation to the habitus. We discuss beer tasting as a formula evoking a new lifestyle, one that produces judgements of taste which reiterate the self-preservation of the social and economic apparatus under an apparent freedom of choice.

KEYWORDS: Clarification. Distinction. Cultural industry. Habitus. Development of the taste. 


\section{ACLARACIÓN Y DISTINCIÓN EN LA ALIMENTACIÓN: UN ANÁLISIS DE LA INDUSTRIA CULTURAL Y LA FORMACIÓN DEL GUSTO POR LAS CERVEZAS ESPECIALES}

RESUMEN: El mercado de cervezas especiales crece en Brasil, contraponiéndose al de las cervezas consideradas comunes. Entre lo refinado y lo grosero, lo que se considere buen o mal gusto se altera en períodos de larga duración. Sin embargo, la distinción permanece en la trama de nuevos habitus de consumo delimitando las costumbres y normas de comportamiento, las elecciones que dan sentido a los variados repertorios y experiencias sociales. En este estudio, analizamos las estrategias de mediación sociocultural de la empresa Ambev en su Centro de Experiencia Cervecera Bohemia. Abordamos las tácticas de la industria cultural en la formación del gusto por cervezas especiales y su relación con el habitus y la distinción. Se trata del problema de la degustación como fórmula generadora de estilos de vida, que produce juicios de gusto que reiteran la autoconservación del aparato social y económico bajo una aparente libertad de elección.

PALABRAS CLAVES: Esclarecimiento. Distinción. Industria cultural. Habitus. Formación del gusto.

\section{REFERÊNCIAS}

ADORNO, Theodor W.; HORKHEIMER, Max. Dialética do esclarecimento: fragmentos filosóficos. Rio de Janeiro: Zahar, 1985.

ALMEIDA, Victor Manoel Cunha de; ROCHA, Almeida Ângela. Efeito pátina: a inscrição de signos conotativos da passagem do tempo nos bens de consumo. Revista Comunicação, mídia e consumo, São Paulo, n. 13, v.5, p. 97-120, jul. 2008.

BARDIN, Laurence. Análise de conteúdo. $2^{\mathrm{a}}$ reimp. da 1 ed. 2011. São Paulo: Edições 70, 2011.

BELTRAMELLI, Maurício. Cervejas, brejas e birras: um guia complete para desmistificar a bebida mais popular do mundo. São Paulo: Leya, 2012.

BOURDIEU, Pierre. A distinção: crítica social do julgamento. 2 ed. Porto Alegre: Zouk, 2015. 
BOURDIEU, Pierre. Gostos de classe e estilos de vida. Questões de Sociologia. Rio de Janeiro: Marco Zero, 1983.

BRANDÃO, Junito de Souza. Mitologia Grega. V. II. Petrópolis: Vozes, 1987.

BRANDÃO, Junito de Souza. Mitologia Grega. V. I. Petrópolis: Vozes, 1986.

BUENO, Maria Lúcia. Da gastronomia francesa à gastronomia global: hibridismos e identidades inventadas. Caderno CRH, Salvador, n.78, v. 29, p.443-462, set/dez. 2016.

CAMARGOS, Marcos Antônio de; BARBOSA, Francisco Vidal. Fusões e aquisições de empresas brasileiras: criação de valor e sinergias operacionais. Caderno de Pesquisas em Administração, São Paulo, n. 2, v. 12, p.99-115, abr/jun. 2005.

CARNEIRO, Henrique. Bebida, abstinência e temperança na história antiga e moderna. São Paulo: Senac, 2010.

CERVIERI JÚNIOR, Osmar; TEIXEIRA JÚNIOR, Job Rodrigues; RANGEL, Galinari; RAWET, Eduardo Lederman; SILVEIRA, Carlos Takashi Jardim da. O setor de bebidas no Brasil. BNDES Setorial, Rio de Janeiro, n. 40, p.93-130, set. 2014.

ELIAS, Nobert. O processo civilizador.Volume I: uma história dos costumes. $2^{\mathrm{a}}$ ed. Rio de Janeiro: Zahar, 2011.

FERNANDES, João Azevedo. Selvagens bebedeiras: álcool, embriaguez e contatos culturais no Brasil colonial. Orientador: Ronaldo Vainfas. 2004. 386f. Tese (Doutorado em História.) Instituto de História, Universidade Federal Fluminense, Niterói, 2004.

FUNARI, Pedro Paulo. Grécia e Roma. 2 ed. São Paulo: Contexto, 2002.

FLANDRIN, Jean-Louis. Tempero, cozinha e dietérica nos séculos XIV, XV e XVI. In: FLANDRIN, Jean-Louis; MONTANARI, Massimo (Org.). História da Alimentação. 8 ed. São Paulo: Estação Liberdade, 2015a. p.478-495.

FLANDRIN, Jean-Louis. Da dietética à gastronomia ou a libertação da gula. In: FLANDRIN, Jean-Louis; MONTANARI, Massimo (Org.). História da Alimentação. 8 ed. São Paulo: Estação Liberdade, 2015b, p.667-688.

FONSECA FILHO, Luciano Roberto Corrêa. História, política e cerveja: a trajetória do lobby das indústrias de cerveja. Orientador: Wagner Pralon Mancuso. 2008. 106f. Dissertação (Mestrado em Ciência Política.) - Faculdade de Filosofia, Letras e Ciências Humanas, Universidade de São Paulo, São Paulo, 2008.

FONTENELLE, Isleide Arruda. O nome da marca: McDonald's, fetichismo e cultura descartável. São Paulo: Boitempo/Fapesp, 2013. 
FRANCO, Maria Laura P. B. Análise de Conteúdo. 4 ed. Brasília: Liber Livro Editora, 2012.

GAZUREK, Marie Océane. Para uma compreensão do ato do consumo. Ponto-e-Vírgula, v. 11, p. 116-130, 2012.

GRIECO, Allen J. A alimentação e classes sociais no fim da Idade Média e Renascença. In: FLANDRIN, Jean-Louis; MONTANARI, Massimo (Org.). História da Alimentação. $8^{\mathrm{a}}$ ed. São Paulo: Estação Liberdade, 2015, p.466-495.

HOUAISS, Antônio; VILLAR, Mauro de Salles. Dicionário Houaiss da Língua Portuguesa. Rio de Janeiro: Objetiva, 2001.

JOANNÈS, Francis. A função social do banquete nas primeiras civilizações. In: FLANDRIN, Jean-Louis; MONTANARI, Massimo (Org.). História da Alimentação. $8^{a}$ ed. São Paulo: Estação Liberdade, 2015, p.54-67.

MARQUES, Teresa Cristina Novaes. A cerveja e a cidade do Rio de Janeiro: de 1888 ao início dos anos 1930. Brasília: EdUNB/Paco Editora, 2014.

MORAES, Roque. Análise de conteúdo. Revista Educação, Porto Alegre, n. 37, v. 22, p.7-32, 1999.

MOREIRA, Sérgio Augusto. O entrelaçamento dialético entre mito e Aufklärung no primeiro capítulo da Dialética do Esclarecimento de Adorno e Horkheimer. Orientadora: Jeanne Marie Gagnebin. 2012. 189f. Dissertação (Dissertação em Filosofia). Programa de Pósgraduação em Filosofia, Pontifícia Universidade Católica, São Paulo, 2012.

SANTOS, Christian Fausto Moraes; CAMPOS, Rafael Dias da Silva. Apontamentos acerca da Cadeia do Ser e o lugar dos negros na filosofia natural na Europa setecentista. História,

Ciências, Saúde - Manguinhos, Rio de Janeiro, n. 4, v. 21, p.1215-1234, out-dez. De 2014.

SANTOS, José Ivan; SANTANA, José Mari.Comida e vinho: harmonização essencial. $3^{\mathrm{a}}$ ed. São Paulo: Senac, 2012.

SCHIVELBUSCH, Wolfgang. Tastes of Paradise: a social history of spices, stimulants, and intoxicants. New York: Vintage Book, 1992.

SCHNEIDER, Marco.A dialética do gosto: informação, música e política. Rio de Janeiro: Circuito, 2015.

SAVARIN, Brillat. A fisiologia do gosto. São Paulo: Companhia das Letras, 1995.

VALENTE, Maria Esther Alvarez. Museus de ciências e tecnologia no Brasil: uma história da museologia entre as décadas de 1950-1970. Orientadora: Maria Margaret Lopes. 2009. $276 f$. Tese (Doutorado em Ensino e História de Ciências da Terra.) - Programa de Pós-Graduação em Ensino e História de Ciências da Terra, Universidade Estadual de Campinas, Campinas, 2009. 
VARGAS, Eduardo Viana. Entre a extensão e a intensidade: corporalidade, subjetivação e uso de drogas. Orientador: Joseph François Pierre Sanchis. 2001. 600f. Tese (Doutorado em Ciências Humanas, Sociologia e Política.) - Faculdade de Filosofia e Ciências Humanas, Universidade Federal de Minas Gerais, Belo Horizonte, 2001.

VENTURINI FILHO, W. G. Bebidas alcoólicas: ciência e tecnologia. São Paulo: Blucher, 2010.

VISSER, Margaret. O ritual do jantar: as origens, evolução, excentricidade e significado das boas maneiras à mesa. Rio de Janeiro: Campus, 1989.

Recebido em 13/05/2019.

Aprovado em 15/09/2020. 